\title{
Providing a Model for Promoting Ethics Education in Schools (combined research)
}

\begin{abstract}
Background and Objective: Given the importance of ethics in the success and performance of Educational organizations, the purpose of this study was to providing a Model for Promoting Ethics Education in Schools.

Materials and Methods: The present study was a combination of exploratory sequencing. The statistical population of the research in the qualitative section was education specialists of Tehran city that among them 20 individuals using purposeful sampling method and Based on saturation principle were selected. In the quantitative section, 300 individuals of second-year high school students in Tehran city were selected as a sample by multi-stage cluster sampling Method using Cochran's formula. Data collection tools in the qualitative section were included semi-structured interviews methods, and in the quantitative section, the researcher-made questionnaire was used That formal validity of which was examined through the experimental implementation of the questionnaire, the content validity of that through the judgment of experts and the construct validity of its using factor analysis Examined. Also, the reliability of the questionnaire was calculated using Cronbach's alpha coefficient and retesting method. Data analysis in the qualitative part was done by content analysis and in the quantitative part exploratory and confirmatory factor analysis and single sample t-test, was performed using SPSS-V22 and Lisrel-V8 / 8 software.

Results: The results showed that Ethics education includes 4 dimensions of educational, social, environmental and doctrinal that components of the educational dimension are (teacher, curriculum, classroom space, school management), components of the social dimension (group values, empathy, social trust, respect for each other), components of the environmental dimension (ethical atmosphere, encouragement and punishment, parents' literacy and income levels, individual socio-economic base) and components of the beliefs dimension are (adherence to Religious values, religious beliefs, chastity).

Conclusion: The research findings showed that the presented model in this study to promote Ethics education in schools is in a good fit.

Keywords: Ethics, educational models, students

Paper Type: Research Article.
\end{abstract}

- Citation (Vancouver): Ghayoomi-Bidhendi A, Etemad-Ahari A. Providing a Model for Promoting Ethics Education in Schools (combined research). Iran J Health Educ Health Promot. Spring 2020;8(3): 272-282. [Persian]x

- Citation (APA): Ghayoomi-Bidhendi A., Etemad-Ahari A. Providing a Model for Promoting Ethics Education in Schools (combined research). Iranian Journal of Health Education \& Health Promotion., 8(3), 272-282 . [Persian]
Aryadokht Ghayoomi-Bidhendi Ph.D Student of Planning Curriculum. Department of Educational Sciences, Islamic Azad University of Rudehen, Roudhen. Iran.

Alaeddin Etemad-Ahari

* Assistant Professor of Planning Curriculum, Department of Educational Sciences, Islamic Azad University of Rudehen, Roudhen. Iran (Corresponding Author). Etemadahari-alaedin@riu.ac.ir

Received: 2020/05/15

Accepted: 2020/06/18

Doi: 10.29252/ijhehp.8.3.282 


\section{ارائه مدلى به منظورارتقاى آموزش اخلاق در مدارس(بثروهشى تركيبى)}

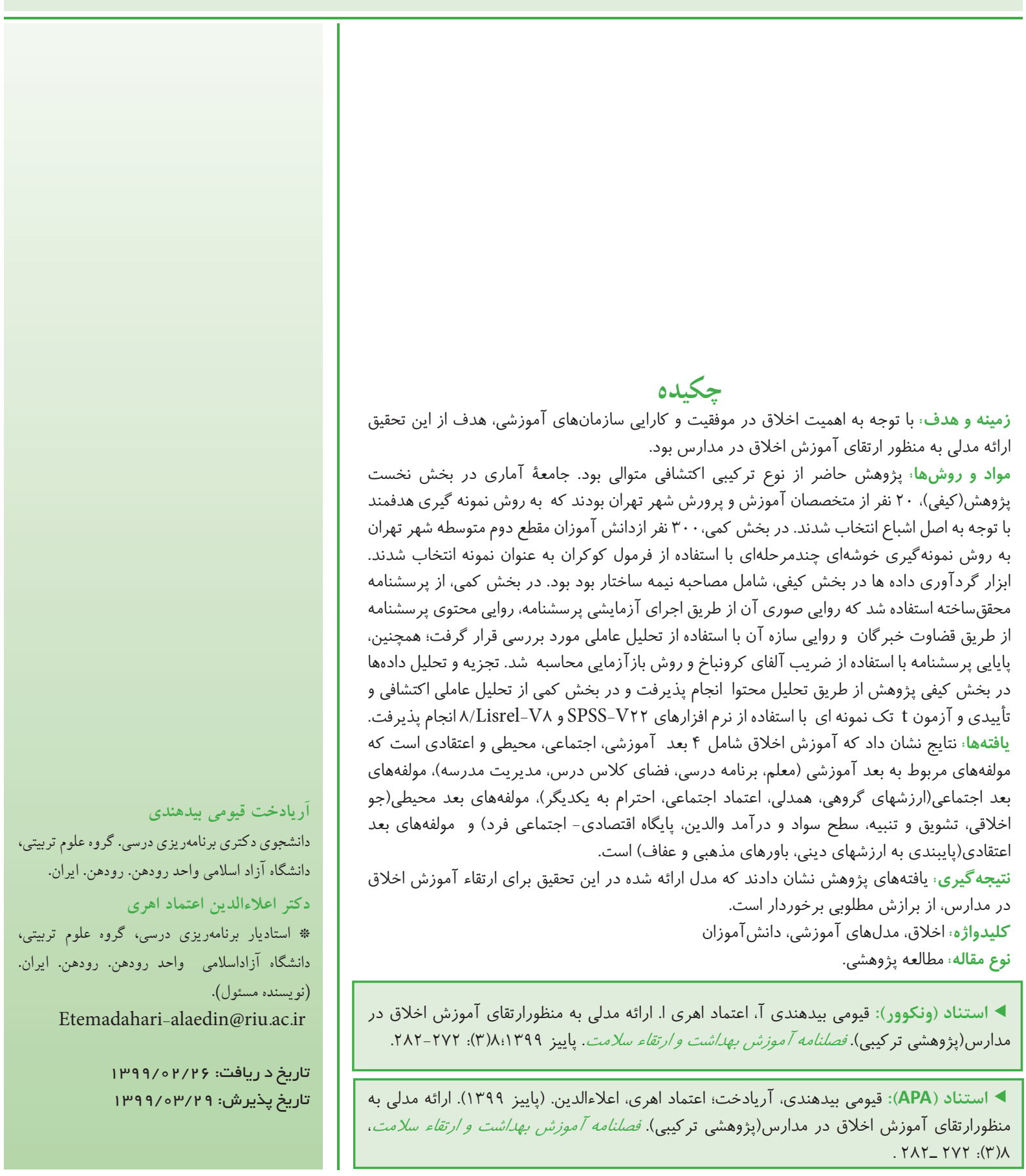


بستكى دارد)(V). بنابر يُزوهشهاى انجام شده مشخص شده است كه

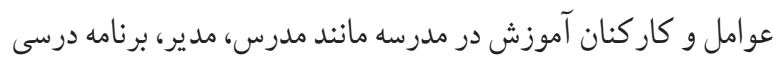

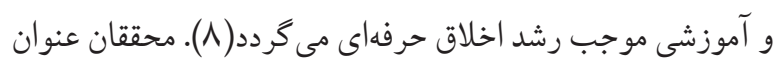

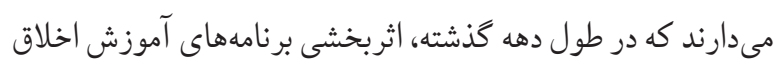

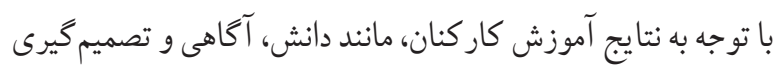

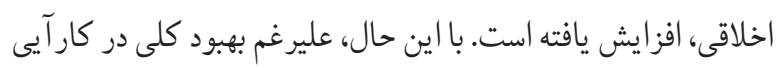

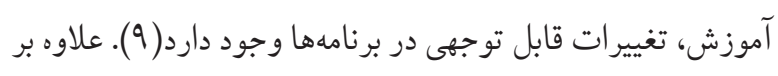

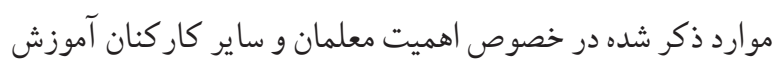
و يرورش در ارتقاء رشد اخلاقى دانش آموزان، دانش آموزان، والدين آدماني

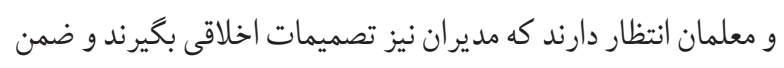

حل و فصل مشكلات، اخلاقى رفتار كنند( • (1).

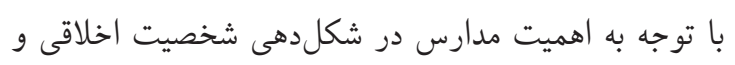

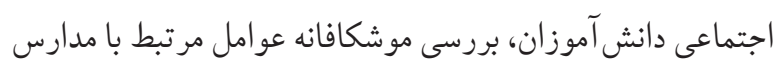

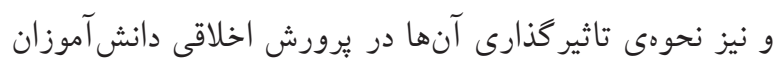

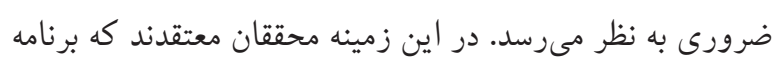

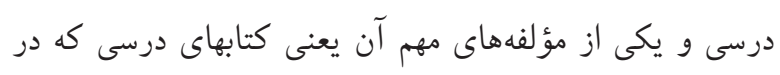

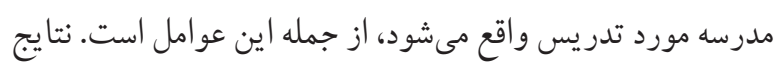

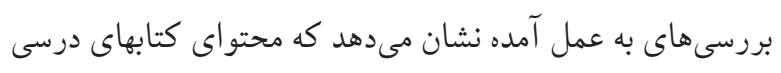

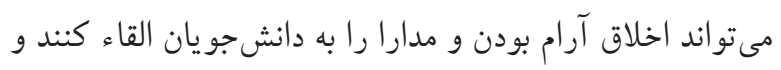

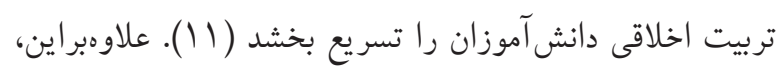
جو حاكم بر مدرسه نيز تاثير شكرفى در شكل گيرى منش اخلاقى دانى دانش آموزان ايفاء مى كند( (I)). Binfet و همكاران( تحقيقى نشان دادند كه جو مدرسه رابطه مثبت و معنادارى با تربيت

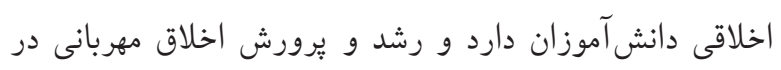

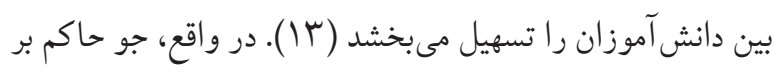
مدرسه از جمله متغيرهايى است كه با هويت اخلاقى و اخلاقيات

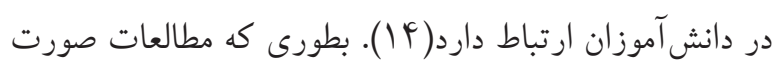
كرفته نيز جو اخلاقى مدارس را موثر بر رشد اخلاق دانش آموزان آندان

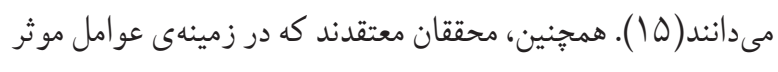

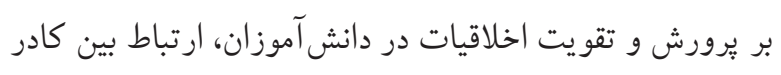

اخلاق در انجام وظايف يكى از موارد مهمى است كه در اكثر جوانب

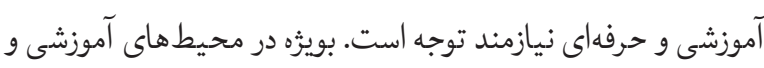
دانشخاهى كه با تربيت و رشد و توسعه افراد جامعه سر و كار دارند، اين ضرورت در اين كونه محيطها بيشتر محسوس مى شود ( (1). اخلاق يكى از شاخههاى مهم فلسفه است كه به ارزشها و فضايل موجود در

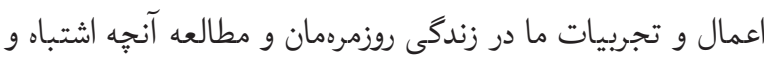

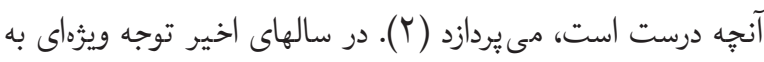

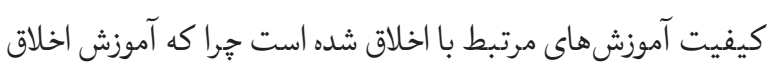

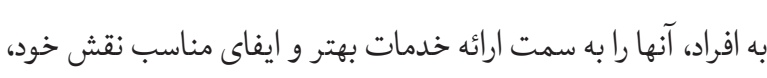
در هنعام مواجهه با جالشهاى اخلاقى هدايت مى كند(ץ). محققان

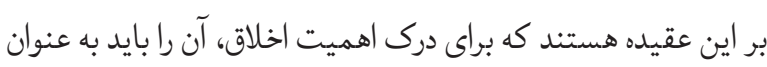

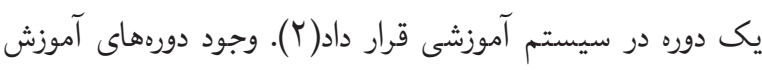
| رسمى در خصوص ارتقاء ارزشهاى اخلاقى، مى تواند توانايى استدلال

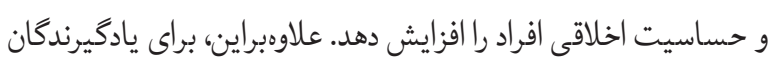

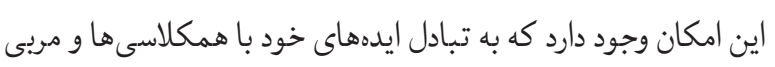

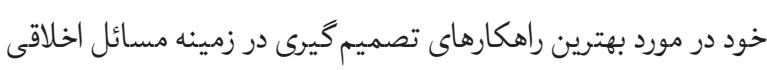

و تجزيه و تحليل ييامدهاى آن بيردازند(Y).

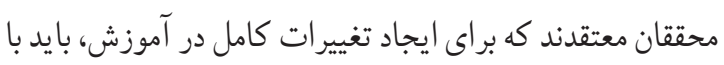
آموزش كار كنان آموزش و يرورش و بو يزهه، معلمان شروع كنيم(ه). به طورى كه به شغل معلمى و تدريس به عنوان يك فعاليت اخلاقى إنى

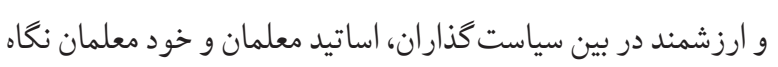
مىشود. در اين راستا به دليل اهميت شغل معلمى در يرورش درئ مفاهيم

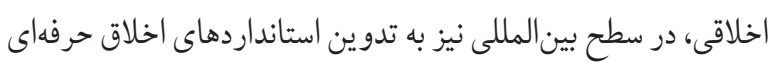

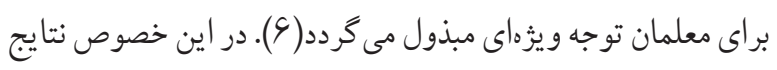

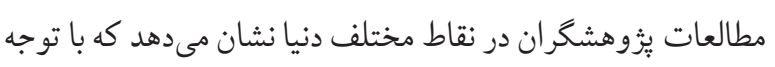
به نقش مهم مدارس در يرورش دانش آموزان، آمادهسازى كود كان

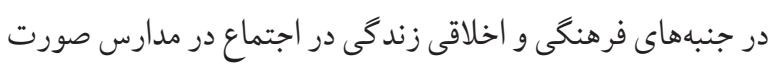

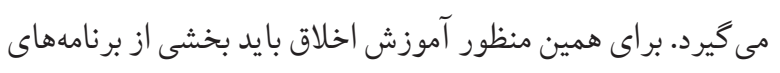

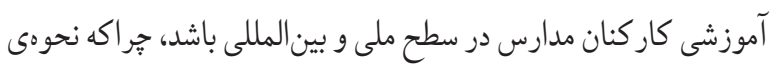

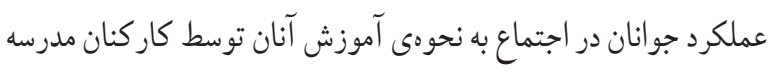


كار مىرود، استفاده كرديد(1)). كه در اين تحقيق بايايى حاصل

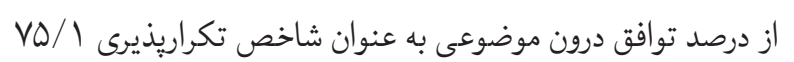
درصد بدست آمد كه بيانكر پِاياى مناسب است.

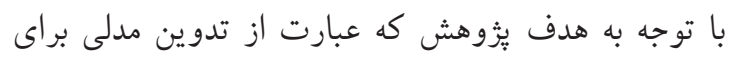

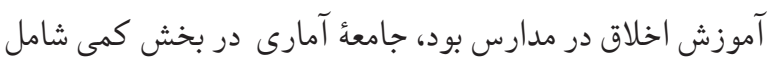

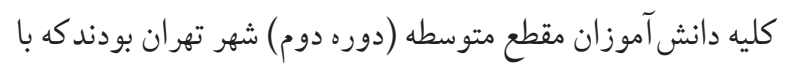

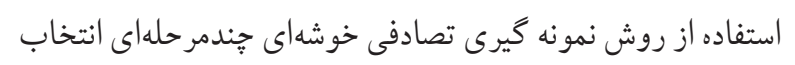

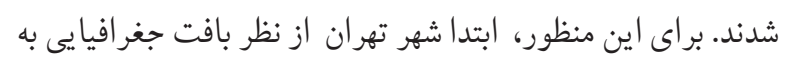

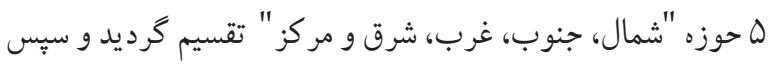

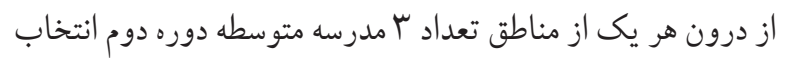

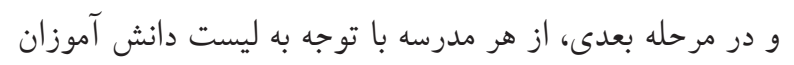

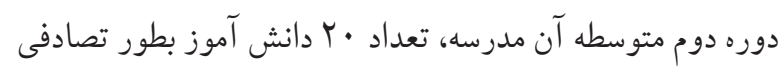

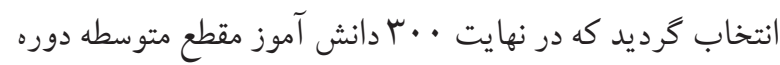
دوم در شهر تهران به عنوان نمونه بخش كمى تحقيق حاضر انتخاب

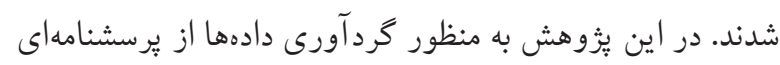

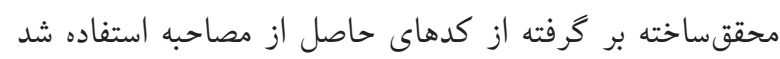
كه با نظرسنجى از دانش آموزان مقاطع متوسطه، تكميل شد. اين درهاي

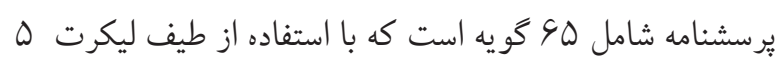

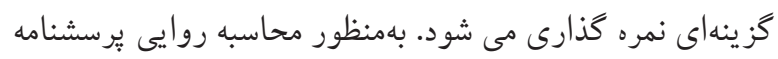

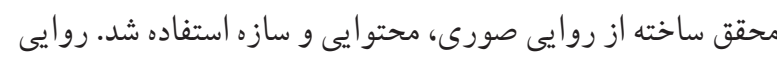

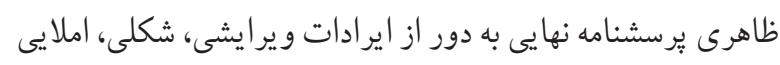

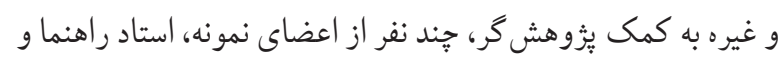

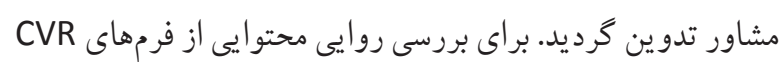

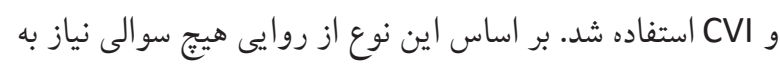

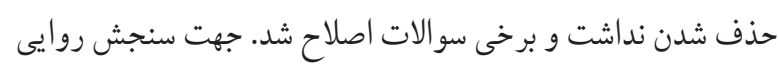

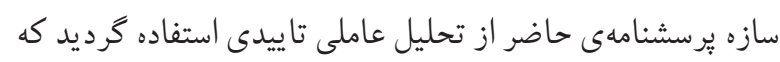
با در نظر گرفتن شاخص هاى برازندگى مدل مذكور، روايى سازهى

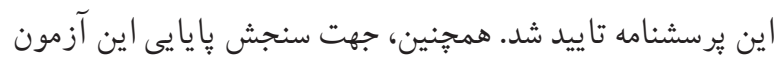

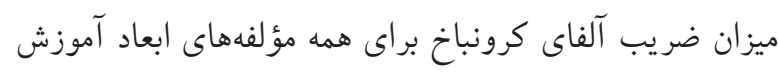

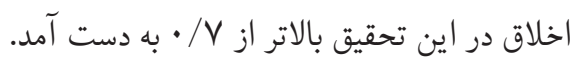

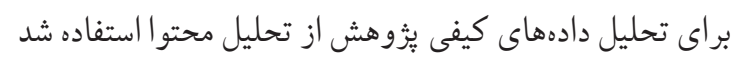

مدرسه و دانش آموزان نيز مهم است. جر اكه علاقه به معلم و ساير

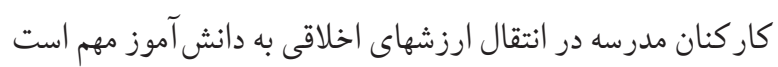

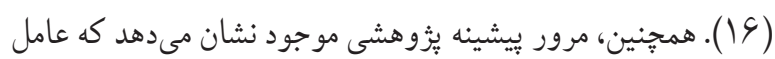

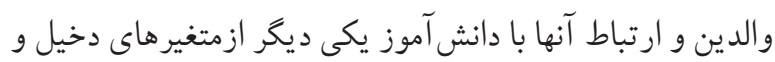

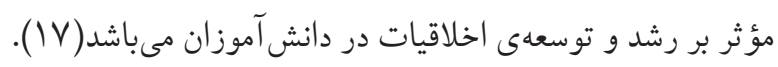

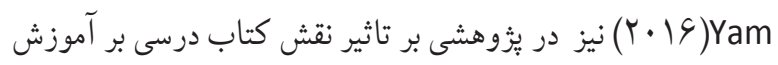

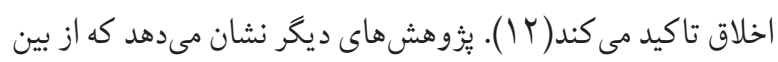

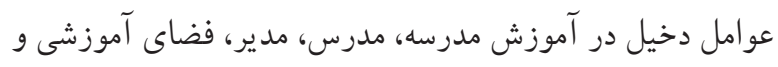
برنامهى درسى در رشد اخلاق حرفهاى نقش جشمخيرى دارند (^).

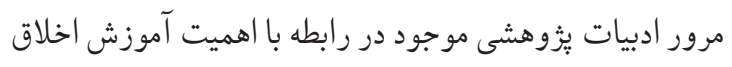

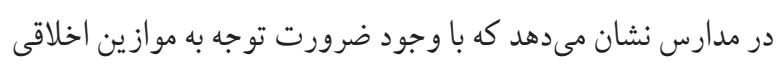

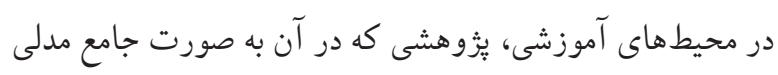

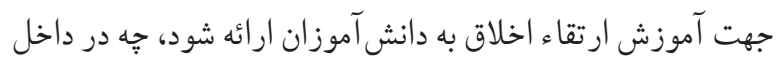

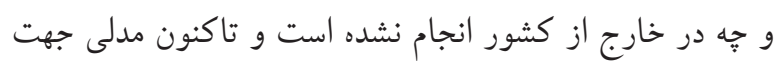

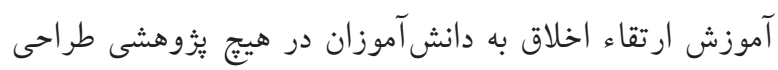

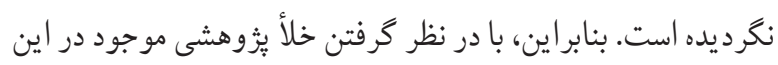

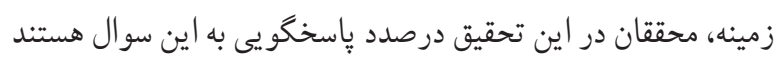

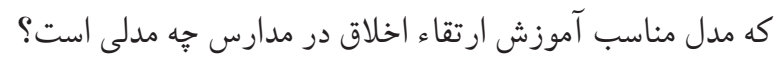
مو اد و روش ها روش يُوهش حاضر بر مبناى ماهيت دادهها آميخته (كمى، كيفى) و وروس

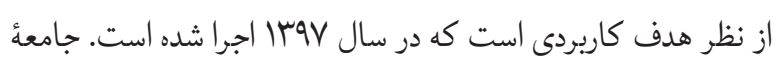
آمارى اين تحقيق در بخش كيفى شامل كاركنان و كارشناسان شاغل در آموزش و يرورش شهر تهران در حوزه آموزش اخلاق بودند. در اين كاركين

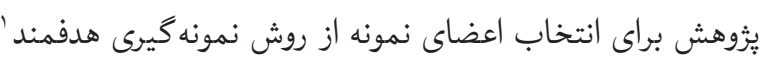

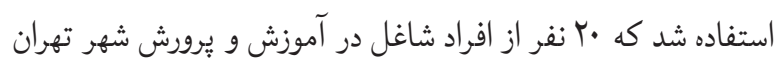

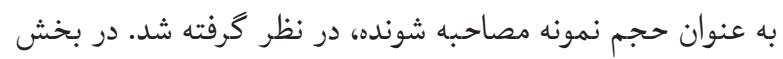
كيفى اين بُزوهش از مصاحبه هاى نيمهساختار يافته استفاده شد. جهت سنجش شاخص تكراريذيرى اطلاعات حاصل از مصاحبه از

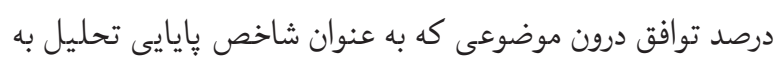


جدول ا: تبيين واريانس مؤلفههاى استخراج شده

\begin{tabular}{|c|c|c|c|c|c|c|c|c|c|}
\hline \multicolumn{3}{|c|}{ مجموع مربع بارهاى جرخش يافته } & \multicolumn{3}{|c|}{ مجموع مربع بارهاى استخراج شده } & \multicolumn{3}{|c|}{ مقادير ويزه اوليه } & \multirow{2}{*}{ مولفه } \\
\hline درصد تجمعى & واريانس & 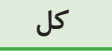 & درصد تجمعى & واريانس & كل & درصد تجمعى & واريانس & كل & \\
\hline $10,9 \wedge \Delta$ & $10,5 \wedge 0$ & $1 \cdot, 190$ & $\Delta F, I V F$ & $\Delta F, I V F$ & ro,rir & $\Delta F, I V F$ & $\Delta F, I V F$ & ro,rı & 1 \\
\hline rq, ror & $\mid r, s, \Lambda$ & $\Lambda, \wedge \Lambda F$ & $\Delta V, 99 Y$ & $ґ, \wedge \backslash \wedge$ & $r, r \wedge r$ & $\Delta V, 99 r$ & $\longleftrightarrow, \wedge \mid \wedge$ & $r, F \wedge r$ & $r$ \\
\hline 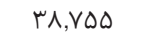 & $9, r^{+} \cdot r$ & $9,11 \mathrm{r}$ & $4 \cdot, 9 \wedge \Lambda$ & r,९9९ & I,VOr & $4 \cdot, 9 \wedge \Lambda$ & $r, 999$ & I,VOH & r \\
\hline FV,I rV & $\Lambda, r \wedge)$ & $\Delta, F F \wedge$ & ST,NIT & r,I TS & I,ए人1 & ST,NIr & r,I TS & $1, \Gamma \wedge 1$ & r \\
\hline$\Delta \Delta, F V Y$ & ᄉ,rro & $\Delta, f \backslash \wedge$ & $S F, \Lambda \Delta F$ & r. Fr & I,rTV & $S F, \Lambda \Delta F$ & $r, \cdot F r$ & $1, r Y V$ & $\Delta$ \\
\hline ST,ITD & $\varsigma, 9 \Delta \mu$ & F,rTo & $99, V 11$ & $1, \wedge \Delta S$ & $1, r \cdot V$ & $s 9, \vee \backslash 1$ & $1, \wedge \Delta S$ & $1, r \cdot V$ & 4 \\
\hline$s \wedge, F \Delta r$ & $G$, rYA & $f, 11 \mu$ & 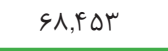 & $1, V \& r$ & 1,1ru & $G \Lambda, F \Delta \mu$ & l,Ver & (1,1 1, & $\checkmark$ \\
\hline$V \cdot, r Y \Lambda$ & $1, V \vee \Delta$ & $r, \xi \cdot \Lambda$ & $99,9 \wedge r$ & $1, \Delta \Gamma_{9}$ & $1,1 \mathrm{ra}^{-}$ & $99,9 \wedge r$ & $1,0 \mathrm{rq}^{\prime}$ & $1,1 \mathrm{rq}$ & $\wedge$ \\
\hline$\vee \backslash, \vee \wedge 1$ & $1, \Delta \Delta r$ & r.r.ı & 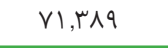 & $1, f \cdot 9$ & $|| r \mid$, & ทा,ए人9 & $1,4 \cdot 9$ & $|| Y \mid$, & 9 \\
\hline$V r, 111$ & 1,rre & $r, r$. & $V Y, S V R$ & $1, r \wedge F$ & 1,111 & $V Y, S V r$ & $1, r \wedge F$ & 1,111 & 1. \\
\hline$V F, Y s Y$ & 1,101 & r,vas & $V^{\mu}, \wedge \Delta \wedge$ & $1,1 \wedge \Delta$ & $1,1 \cdot 9$ & $V^{\mu}, \wedge \Delta \Lambda$ & $1,1 \wedge \Delta$ & $1,1 \cdot 9$ & 11 \\
\hline VQ,rN। & 1,111 & $r, V \Delta F$ & $V \Delta, \cdot r \Delta$ & $1,1 \subseteq V$ & $1,1 \ldots$ & $v \Delta, \cdot r \Delta$ & $1,1 \& V$ & $1,1 \ldots$ & Ir \\
\hline Vद, ז৭৭ & $1, \cdot 11$ & T,SYF & VG,1 Hs & $1,11 r$ & $1, \cdot 91$ & $V 4,1{ }^{\prime}$ & $1,11 r$ & $1, \cdot 91$ & 11 \\
\hline$V V, r q r$ & $\cdot, 994$ & r,orq & $V Y, Y I T$ & $1, \cdot \vee G$ & $1, .9 r$ & $V V, Y I r$ & $1, \cdot \sqrt{ }$ & $1, \cdot 9 r$ & if \\
\hline \multirow[t]{9}{*}{$\checkmark \wedge, Y \cdot V$} & $\cdot, \wedge 10$ & r.rFs & $\checkmark \wedge, r \cdot V$ & $\cdot, 994$ & $1, \cdot \Delta$ & $\checkmark \wedge, r \cdot V$ & $\cdot, 99 f$ & $1, \cdot \Delta \cdot$ & 10 \\
\hline & & & & & & $\$ ৭, ৭ \wedge r$ & $1, \Delta r q$ & $\cdot, 99 \mathrm{~F}$ & 19 \\
\hline & & & & & & $\vee 1$, ए人 & $1, f \cdot 9$ & $\cdot, 914$ & IV \\
\hline & & & & & & $V r, S V r$ & $1, r \wedge F$ & $\cdot, \wedge \mu \Delta$ & 11 \\
\hline & & & & & & $V^{\mu}, \wedge \Delta \Lambda$ & $1,1 \wedge \Delta$ & $\cdot, \vee \vee$ & 19 \\
\hline & & & & & & $V \Delta, \cdot r \Delta$ & $1,1 \& V$ & $\cdot, \vee \triangle \wedge$ & $r$. \\
\hline & & & & & & & & & $\ldots$ \\
\hline & & & & & & १৭,१९५ & $\cdot, \cdot \varphi \wedge$ & $\cdot, \cdot r \Lambda$ & $s q$ \\
\hline & & & & & & $1 \ldots$ & $\cdot, \cdot r V$ & $\cdot, \cdot r r$ & 90 \\
\hline
\end{tabular}

كه مراحل تحليل دادهاى كيفى گردآورى شده، از طريق كدگذارى يافتهها

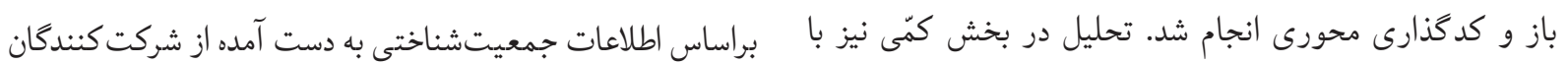

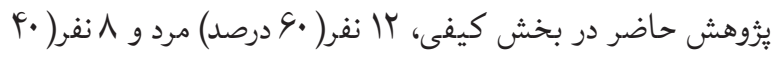

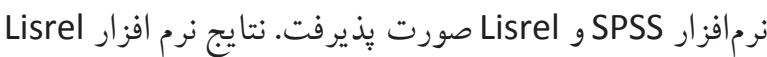

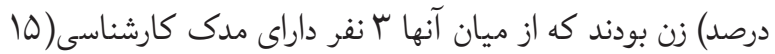
در قالب روش مدلسازى معادلات ساختارى مورد استفاده قرار

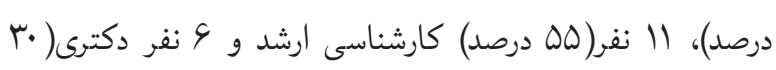
درصد) بودند. همجنِين، از ميان شركت كنندكان بخش كمى يُّوهش

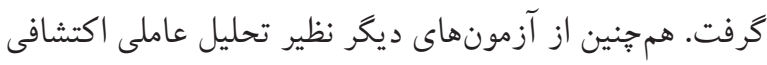
و آزمون t تك نمونه اي نيز بهره خرفته شد.

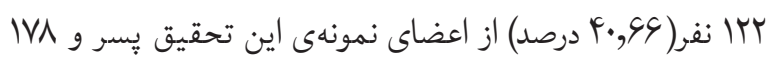
در فرايند انجام تحقيق حاضر برخى ملاحظات اخلاقى مورد توجه

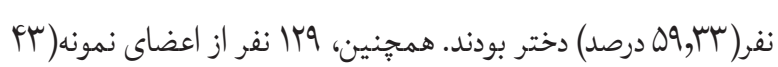
قرار كرفت كه مهمترين آنها توضيح اهداف تحقيق به شركت كنند ماصنان

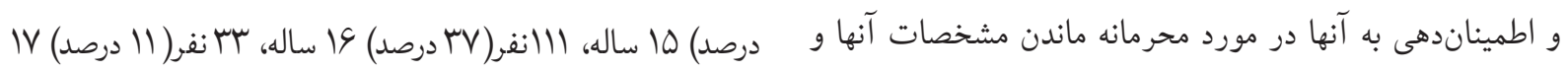

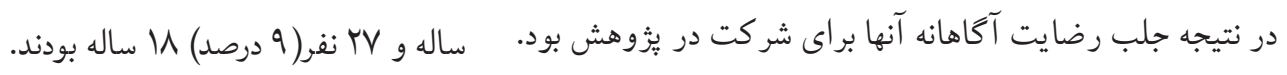


جدول rا: مولفه هاى استخراج شده بعد از تحليل عاملى اكتشافى

\begin{tabular}{|c|c|c|}
\hline تعداد شاخص & 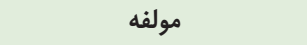 & بعد \\
\hline$\Delta$ & 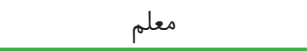 & \multirow{4}{*}{ آموزشى } \\
\hline$\Delta$ & برنامه درسى & \\
\hline$\Delta$ & فضاى كلاس درس & \\
\hline$\Delta$ & مديريت مدرسه & \\
\hline r & ارزشهاى گروهى & \multirow{4}{*}{ |جتماعى } \\
\hline r & 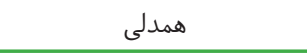 & \\
\hline r & اعتماد اجتماعى & \\
\hline f & احترام به يكديگر & \\
\hline$\Delta$ & جو اخلاقى & \multirow{4}{*}{ محيطى } \\
\hline r & تشويق و تنبيه & \\
\hline r & سطح سواد و در آمد والدين & \\
\hline$\Delta$ & پايغاه اقتصادى - اجتماعى فرد & \\
\hline$\Delta$ & هِايبندى به ارزشهاى دينى & \multirow{3}{*}{ اعتقادى } \\
\hline r & باور هاى مذهبى & \\
\hline$\Delta$ & 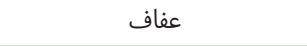 & \\
\hline
\end{tabular}

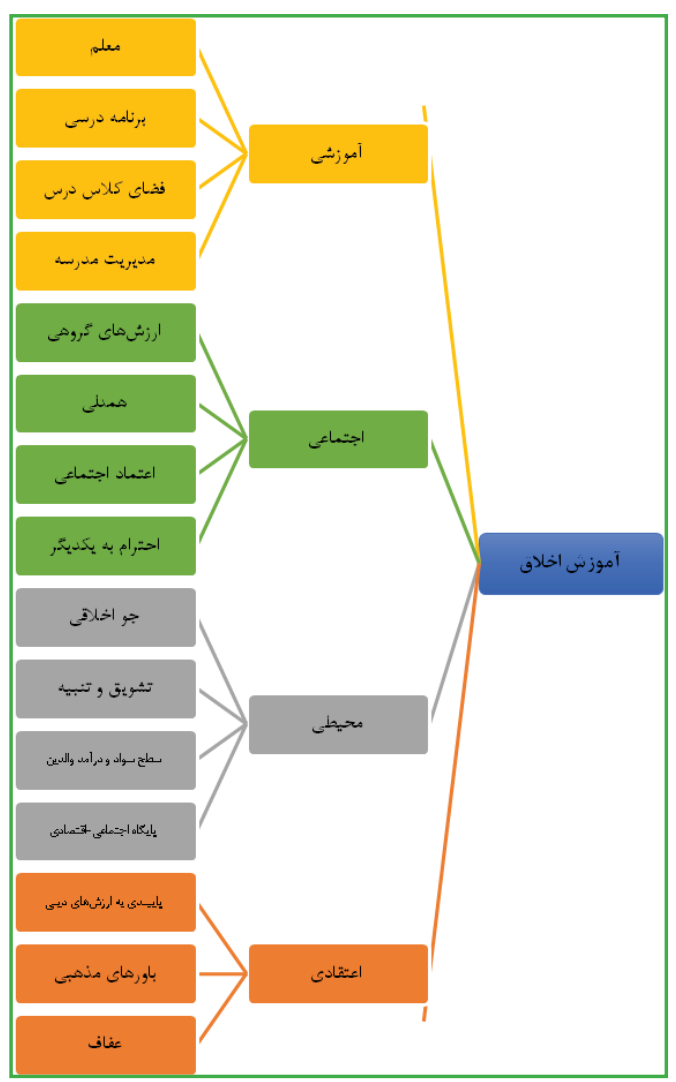

شكل ا : الغَوى نهايى ابعاد و مؤلفههاى آموزش اخلاق
تحليل عاملى اكتشافى به منظور استخراج مولفهاى آموزش اخلاق از تحليل عاملى اكتشافى آلى

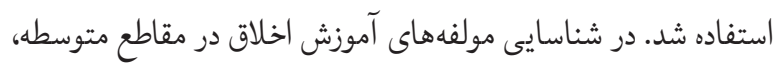

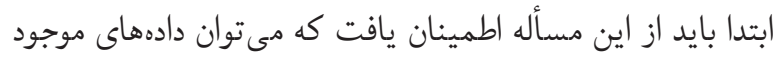
را براى تحليل به كار برد يا به عبارتى، آيا تعداد دادههاى مورد نظر

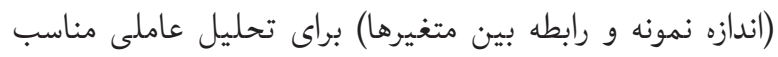

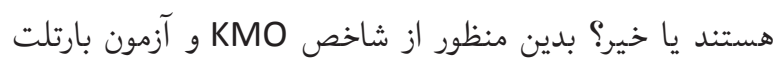

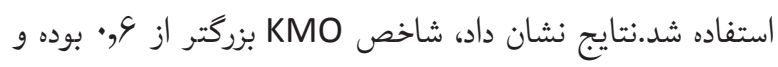

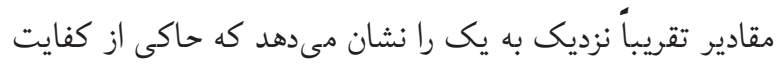

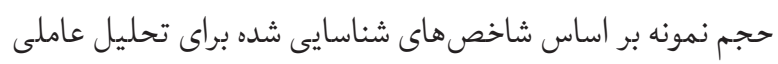

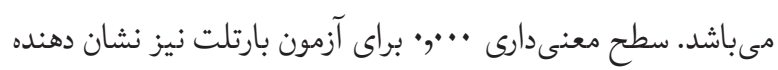

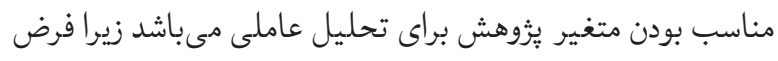

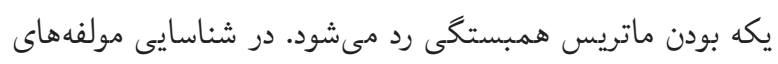

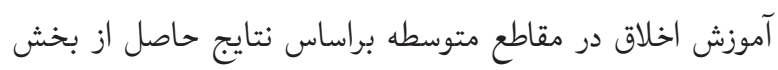

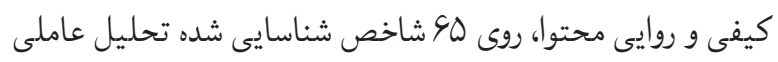

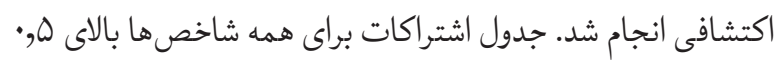

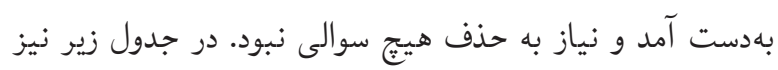

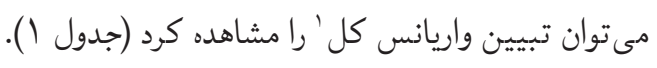

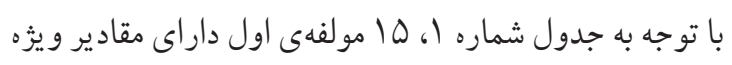

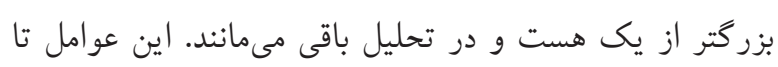

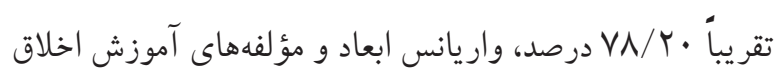

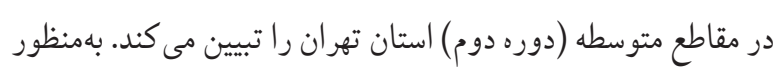

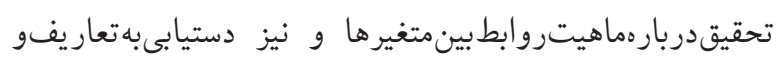

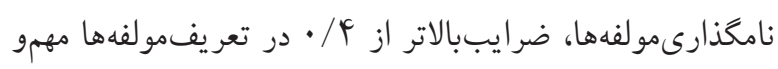

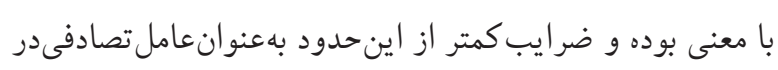

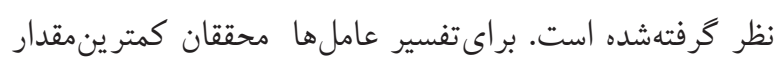

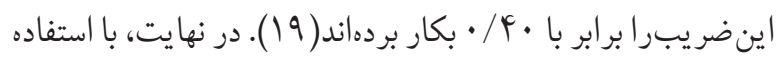

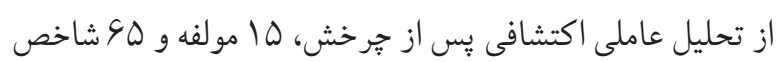

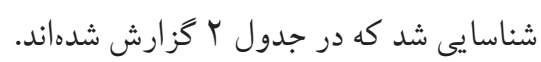


همانطور كه در جدول فوق مشاهده مىشود، با استفاده از تحليل براى اينكه بدانيم وضعيت ابعاد و مؤلفههاى شناسايى شده در

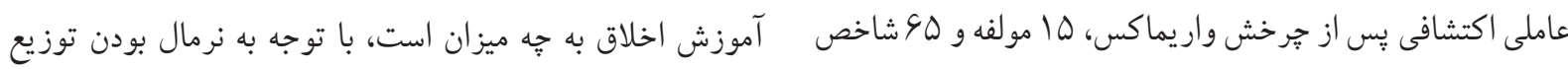

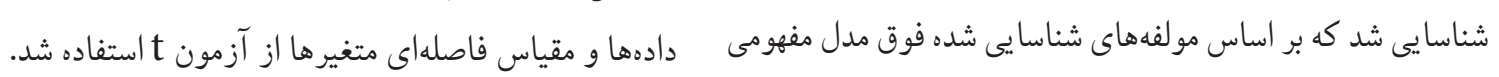

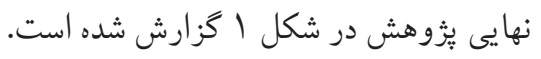

جدول ّا: آزمون تى تك نمونهاى به منظور بر رسى وضعيت موجود مولفهاى آموزش اخلاق

\begin{tabular}{|c|c|c|c|c|c|c|c|}
\hline \multirow{3}{*}{ بعد } & \multirow{3}{*}{ مولفه } & \multicolumn{6}{|c|}{ ارزش آزمون= } \\
\hline & & \multirow{2}{*}{ مقدار تى } & \multirow{2}{*}{ درجه آزادى } & \multirow{2}{*}{$\begin{array}{c}\text { سطح معنادارى (دوامنه) } \\
\text { سطنه }\end{array}$} & \multirow{2}{*}{ اختلاف ميانغين } & \multicolumn{2}{|c|}{ فاصله اطمينان ه9 درصد از } \\
\hline & & & & & & حد بايين & حد بالا \\
\hline \multirow{4}{*}{ آ آموزشى عوامل } & معلم & $1 \cdot, \Delta V^{c}$ & rq9 & $\cdot, \cdots$ & $\cdot, f \wedge 1$ & ( & $\cdot, \Delta \vee I$ \\
\hline & برنامه درسى & $r, \wedge 9 r$ & rq9 & $\cdot, \cdots r$ & $\cdot, \| \mu$ & $\cdot, \cdot F F$ & • \\
\hline & فضاى كلاس درس & $1 \cdot$, FAr & rq9 & $\cdot, \cdots$ & • & • & $\cdot, \Delta \mu \wedge$ \\
\hline & مديريت مدرسه & $f, f \mid f$ & rq9 & $\cdot, \cdots$ & • rYq & $\cdot, I Y V$ & ו ו וץ, • \\
\hline \multicolumn{2}{|c|}{ عوامل آموزشى } & $\vee, \varsigma^{\mu}$. & r99 & $\cdot, \cdots$ & מ & $\cdot, Y F 1$ & $\cdot, r \cdot q$ \\
\hline \multirow{4}{*}{ 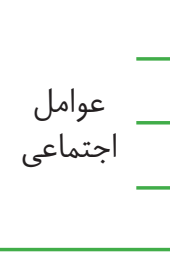 } & ارزشهاى گروهى & $r, \cdot r \wedge$ & raq & $\cdot, \cdot r$ & · & $\cdot, \cdot \Delta F$ & $\cdot, r \Delta r$ \\
\hline & همدلى & 1,V\& & raq & $\cdot, \cdots 9$ & $\cdot, \cdot \wedge \Lambda$ & $\cdot, \cdot 1$ & $\cdot, 1 \wedge 9$ \\
\hline & اعتماد اجتماعى & $\wedge, r \vee \wedge$ & r99 & $\cdot, \cdots$ & $\cdot, 4 \cdot 1$ & $\cdot, r \cdot \vee$ & $\cdot, 490$ \\
\hline & احترام به يكديكر & $\vee, 19 r$ & r99 & $\cdot, \cdots$ & $\cdot$, rYA & • & $\cdot,+\backslash \wedge$ \\
\hline \multicolumn{2}{|c|}{ عوامل اجتماعى } & D,FYV & r99 & $\cdot, \cdots$ & $\cdot$, rFr & $\cdot, 1 \Delta \Delta$ & إسז, • \\
\hline \multirow{4}{*}{ محيطى عوامل } & جو اخلاقى & 4,199 & rq9 & $\cdot, \cdots$ & $\cdot, r \Delta q$ & $\cdot, I V \mathrm{~V}$ & $\cdot$, rFr \\
\hline & تشويق و تنبيه & $F, Y F T$ & r9q & $\cdot, \cdots$ & $\cdot, 1 \wedge 9$ & $\cdot, 1 \cdot 1$ & $\cdot, r V V$ \\
\hline & سطح سواد و در آمد & $r, q \wedge \vee$ & rq9 & $\cdot, \cdots$ & $\cdot r \mid r$ & ( & $\cdot, r \cdot l$ \\
\hline & "ِايگاه اقتصادى - & 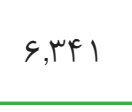 & rq9 & $\cdot, \cdots$ & $\cdot, r \wedge \wedge$ & $\cdot, 199$ & $\cdot, r V V$ \\
\hline \multicolumn{2}{|c|}{ عوامل محيطى } & $\Delta, \wedge \mu$. & $r 99$ & $\cdot, \cdots$ & • r r & $\cdot, 1 \Delta \mathrm{V}$ & • r IV \\
\hline \multirow{3}{*}{ عوامل اعتقادى } & ارز & $\wedge, \wedge \wedge 1$ & rq9 & $\cdot, \cdots$ & $\cdot, r \cdot 4$ & ( & $\cdot, f 94$ \\
\hline & باورهاى مذهبى ـ عو & $\vee, \wedge \cdot \Delta$ & r99 & $\cdot, \cdots$ & س س س, • & $\cdot, r V Y$ & $\cdot, f \Delta \Delta$ \\
\hline & عفاف & $r, F \Delta S$ & rq9 & $\cdot, \cdot 10$ & $\cdot, 11 \cdot$ & $\cdot, \cdot Y r$ & $\cdot, 191$ \\
\hline \multicolumn{2}{|c|}{ عوامل اعتقادى } & G,qup & rq9 & $\cdot, \cdots$ & ש ז ז, • & $\cdot, r)$ & $\cdot, r \vee G$ \\
\hline
\end{tabular}

همانطور كه در جدول مشاهده مىشود، سطح معنادارى در تأييد مىشود. همجنين، با توجه به اختلاف ميانگين كه مقاديرى

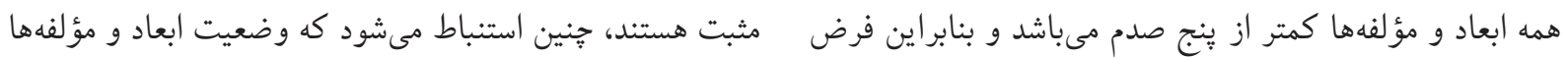

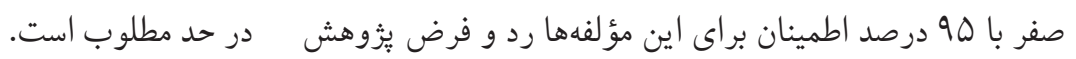


يا بزرگتر از •9/ • باشد تا مدل مورد نظر پذيرفته شود. همجنين، تحليل عاملى تاييدى

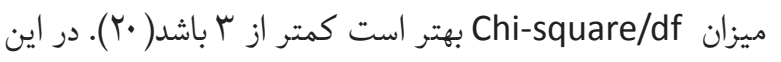

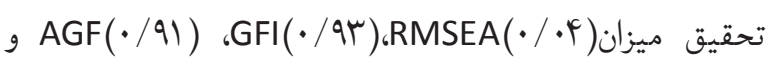
به-دست آمد كه نشان مى دهد مدل Chi-square/df (Y/Or) ارائه شده در اين تحقيق از برازش مطلوبى برخوردار است.

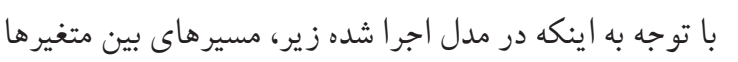

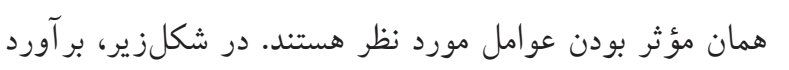

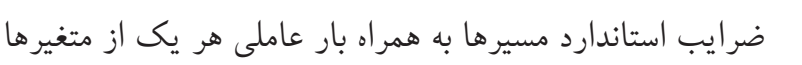

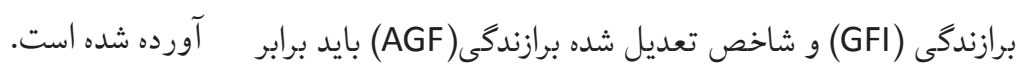

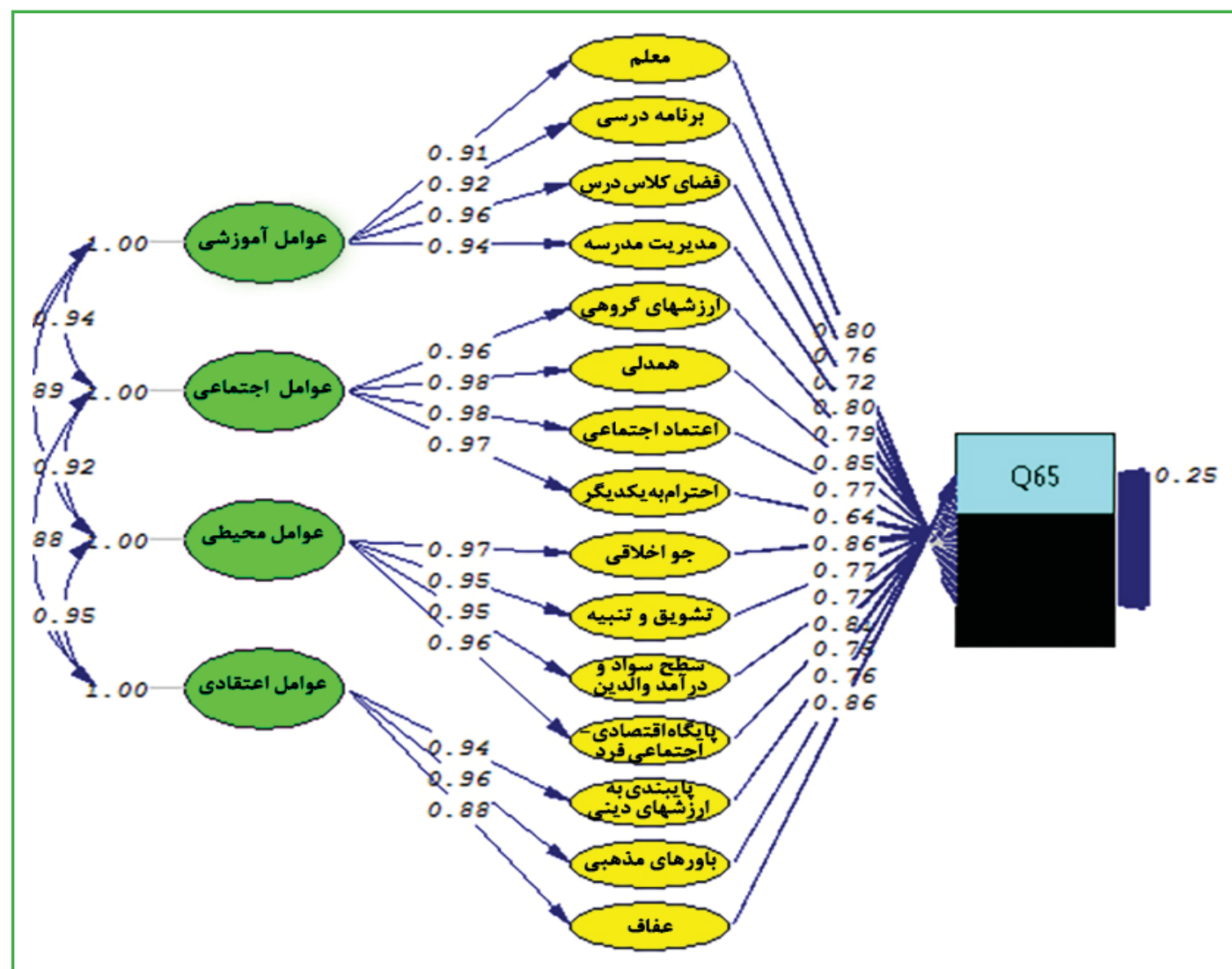

Chi-Square=5053.49, df=1994, P-value=0.05924, RMSEA=0.048

شكل r: مدل ساختارى يزوهش در حالت تخمين ضرايب استاندارد

همانطور كه در شكلهاى بالا نشان داده شده است، كليهى تمام بارهاى عاملى از وضعيت مطلوبى برخوردار بوده و قابليت

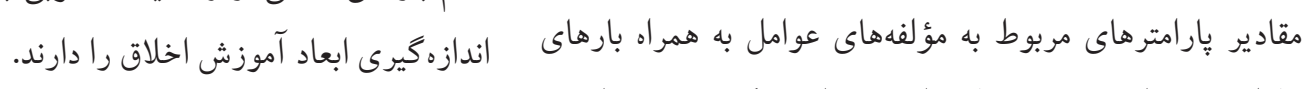

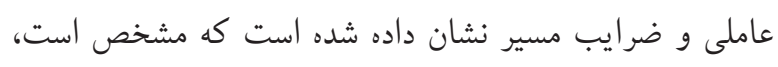


ارزشى دانش آموزان تأثير زيادى دارد(9 19). علاومبراين، Smetana

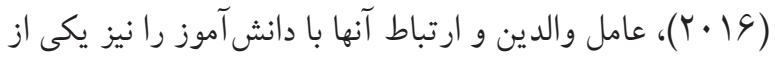

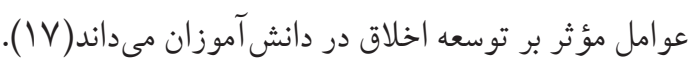

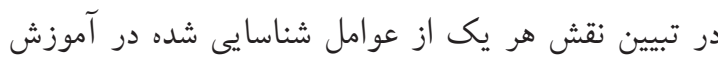

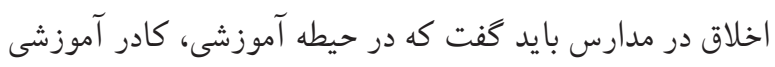
مدارس مى توانند تاثيرات بسزايى بر ساختار و شكلدهى دهى رفتار دانش آموزان داشته باشند، كه براى تحقق اين مهم، در ابتدا خود

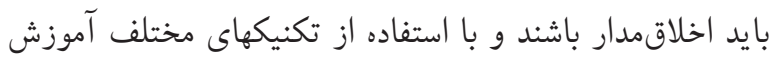

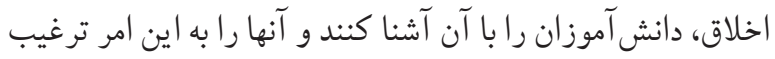

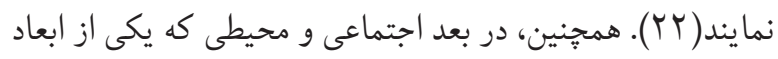

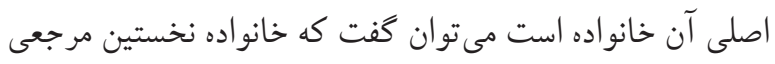
است كه شخصيت فرد در آن شكل مى گيرد و بانفوذترين مرجع

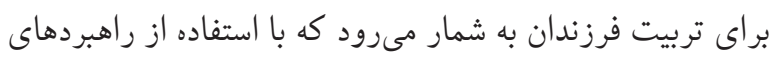
متعدد درصدد است تا مفاهيم اجتماعى و اخلاقى را در فرزندان خود نهاد ينه كند. بهطورى كه تحقيقات متعدد هم نشان مى دهد كه

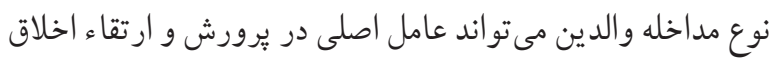

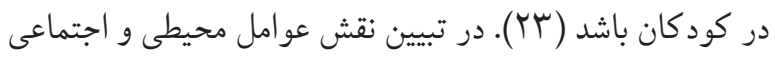

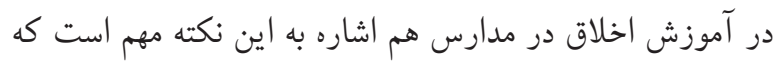
يكى از جنبههاى مهم رفتار اخلاقى علاقه و توجه به ديكران است.

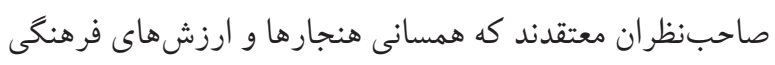

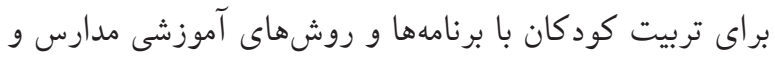

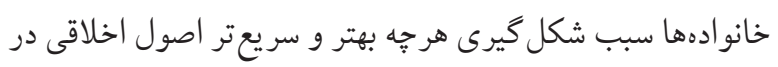

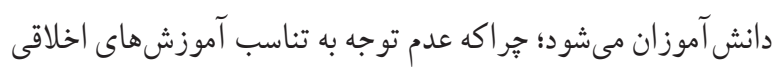

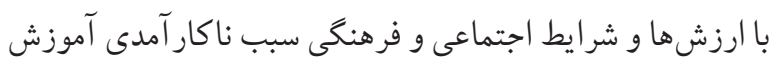

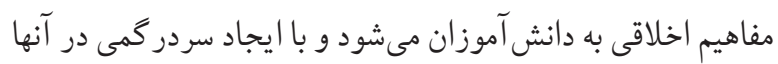

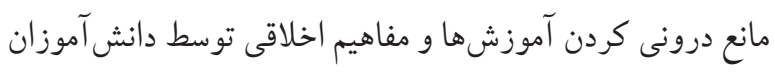

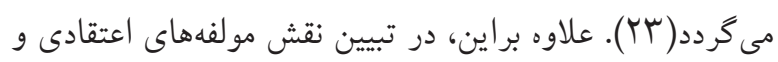

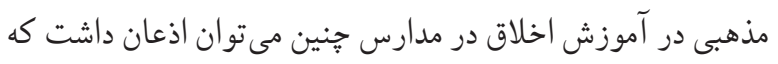

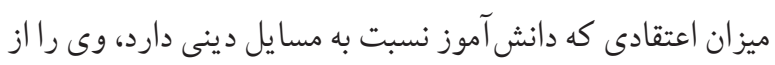

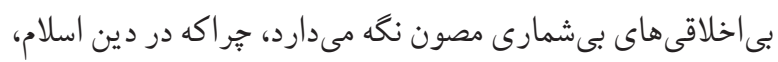

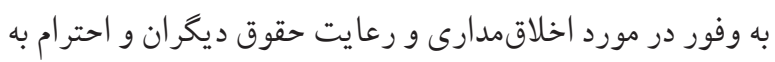

هدف يُوهش حاضر ارائه مدلى بهمنظور ارتقاء آموزش اخلاق در

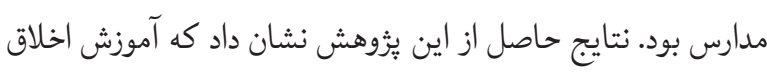

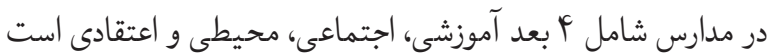

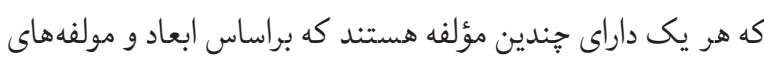

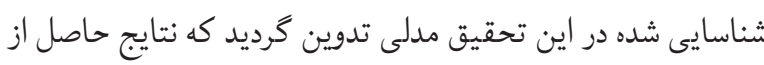

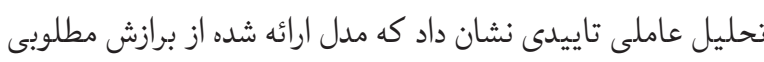

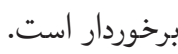

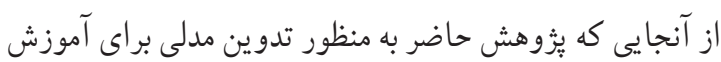

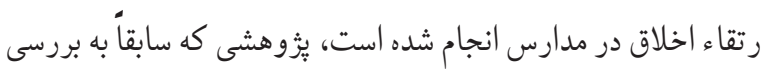

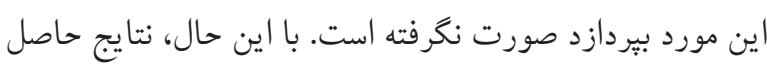

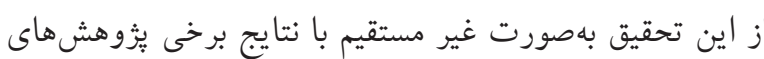

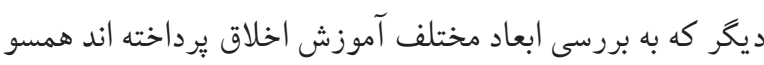

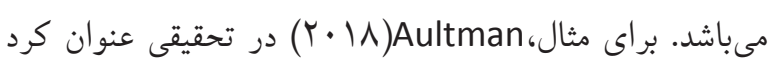
كه در آموزش اخلاق حرفهاى به دانشجويان، قانون اخلاقى در دران

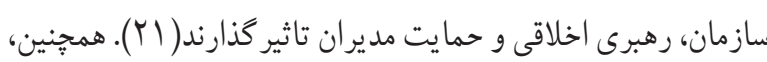
نشان داد كه عوامل آموزش در مدرسه (Y. IV)Gluchmanová

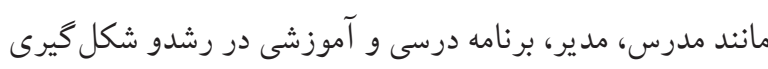

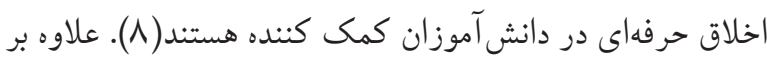

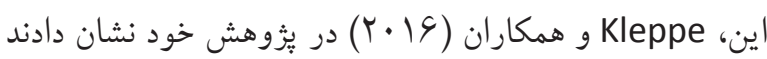
كه محتواى كتابهاى درسى مىتو اند اخلاق آرام بودن و مدارا را به به

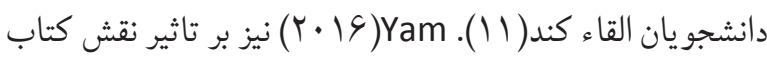
درسى بر آموزش اخلاق تاكيد مى كند. عامل مهم ديخر در مدرسه

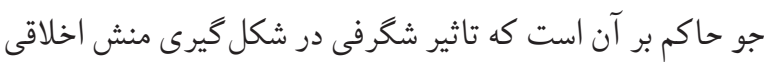

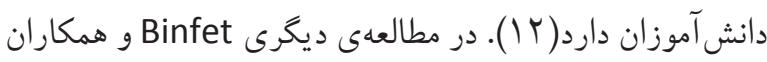

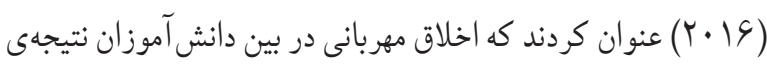

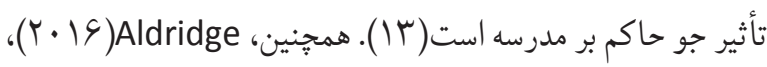

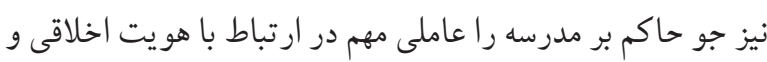

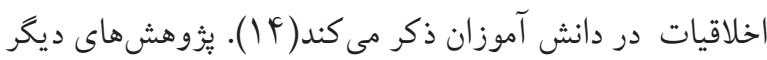

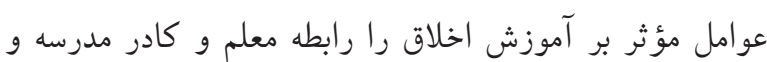

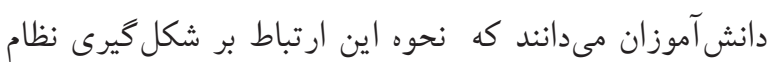


جو اخلاقى، تشويق و تنبيه، سطح سواد و درآمد والدين، پايخاه

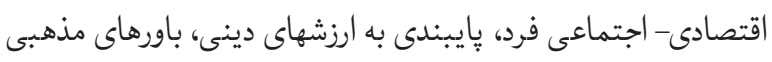

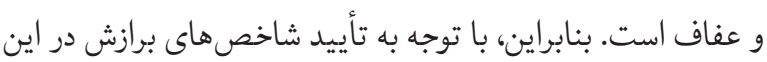

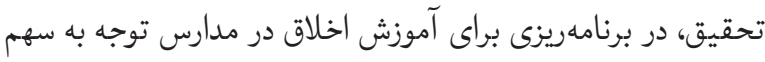

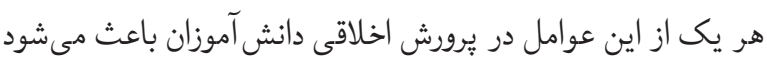

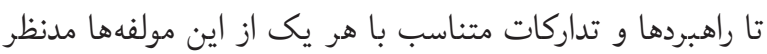
مسئولان و محققان قرار گيرد. در تحقيقات آتى در اين زمينه هم

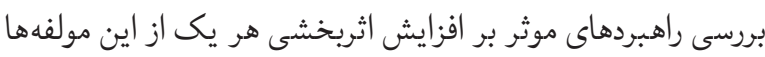

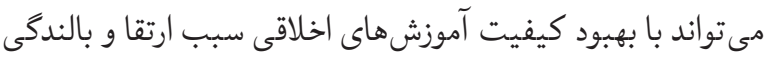

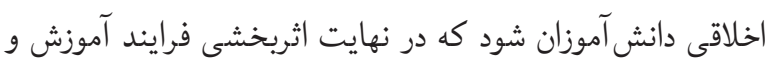

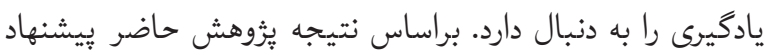
مى شود كه كاركاهها و جلساتى بواى كاركنان مدارس اعم از مديران

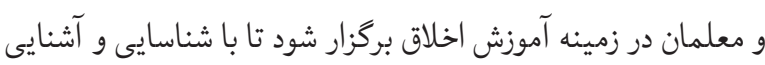

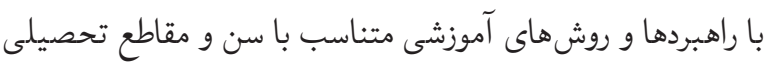
دانش آموزان به آموزش مطلوب و موثر اخلاق به آنها بيردازند.

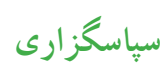

محققان يُزوهش حاضر از كليهى افراد شركت كننده در اين يُزوهش

$$
\text { تعارض منافع تشكر و قدردانى خود را اعلام مى كنند. }
$$$$
\text { هيج گونه تعارض منافعى بين نويسندگان وجود ندارد. }
$$

\section{References}

1- Faragbakhsh F, Nuhi E, Zolali F. The importance of ethics in education and the level of complying with it from the perspective of nursing students of Kerman University of Medical Sciences. J Educ Ethics Nurs. 2016;5(1):1-7

2- Gülcan, N. Y. Discussing the importance of teaching ethics in education. ProcediaSocBehav Sci.2015; 174, 26222625.

3- Bostani S. Strategies to promote professional ethics in nursing education system. Strat. Med. Educ.2015; 2 (2):1322.

4- Cannaerts N, Gastmans C, deCasterlé BD. Response to Commentary (1): Effectiveness of Nursing EthicsEducation: Much More Research Needed. Nurs. Ethics.2014; 21(6):743.

5- Velea, S., \&Farca, S. Teacher's Responsibility in Moral and Affective Education of Children. ProcediaSocBehavSci,
آنها توصيه شده است. مرور منابع دينى و اخلاقى نشان مىدهد كه

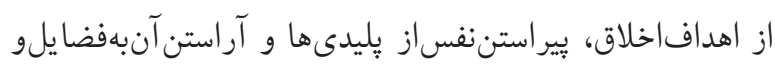

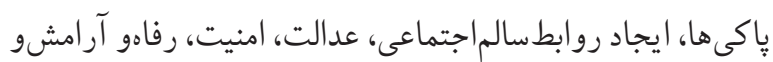

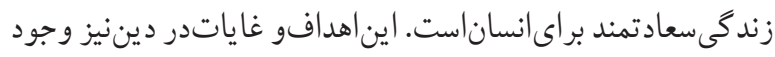

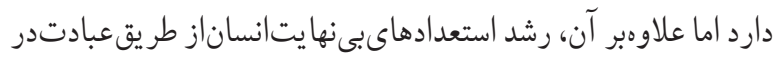

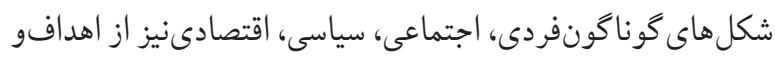

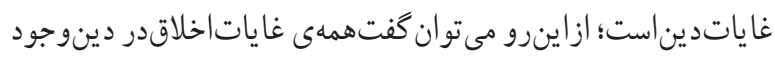
دارد و دين در تعيين هدف والاى اخلاقى نيز نقش تعيين كننده

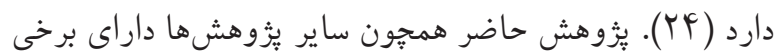

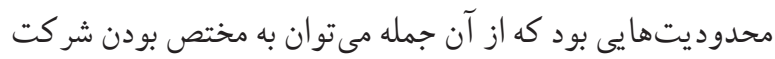

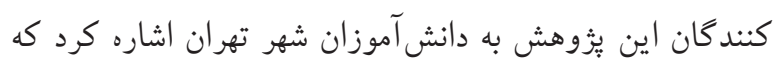

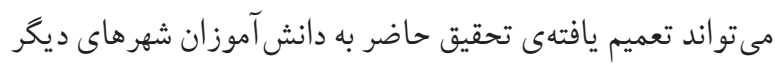

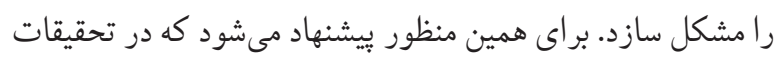

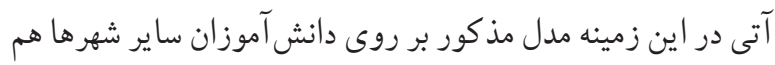
اعتبار يابى و روايى سنجى شود. نتيجاء كيرى تحقيق حاضر نشان داد كه از ديدگاه كاركنان شاغل در آموزش و

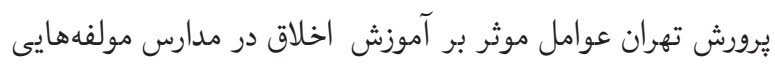
همجِون؛ معلم، برنامه درسى، فضاى كلاس درس، مديريت مدرسه،

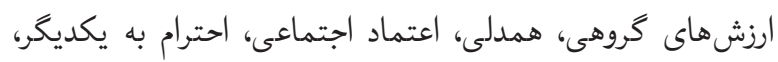

2013; 76, 863-867.

6- Pantić, N., \&Wubbels, T. The role of teachers in inculcating moral values: Operationalisation of concepts. J Beliefs Values. 2012; 33(1), 55-69.

7- Johnson AE. Examining the relationbetween ethnic identity and competence amongLatino early adolescents. [Ph.D. Thesis]. USA:Texas State University, 2015.

8- Gluchmanová M. Theoretical and practical aspects of a professional ethics of teaching. Hum Relat.2017; 27(1):7581.

9- Visser W, Mclntosh M \& Middleton C. Research on corporate citizenship in Africa: A ten-year review (19952005). In Corporate Citizenship in Africa. Routledge, 2017. (pp. 18-28)

10- Rezapour, Y. KHeradmand, T \&SHahedi, S. Effectiveness of Moral Intelligence on Social Performance and Behavioral 
Problems. EthicScitech. 2017; 12 (4):48-59.(In Persian).

11- Kleppe LC, Heggen K \&Engebretsen E. Nursing textbooks' conceptualization of nurses' responsibilities related to the ideal of a holistic view of the patient: A critical analysis. NurseEducPract. 2016; 6(3): 106-115.

12- Yam, S. Y. S. Education and Transnational Nationalism: The Rhetoric of Integration in Chinese National and Moral Education in Hong Kong. Howard J.Commun. 2016; 27(1), 38-52.

13- Binfet J T, Gadermann A M \&Schonert-Reichl K A. Measuring kindness at school: Psychometric properties of a School Kindness Scale for children and adolescents. Psycho Sch.I. 2016; 53(2), 111-126.

14- Aldridge J M, Ala'i KG \& Fraser BJ. Relationships between school climate and adolescent students' self-report of ethnic and moral identity. LearnEnviron Res.2016; 19(1), 1-15.

15- Kadivar P, Kohoulat N, Abdolahi M H \&Khoshbakht F. Perception of School Moral Atmosphere and Elementary Students' Moral Development. "Int. J. Sch. Health. 2016; 3(4): 1-6.

16- Kohi, Elham. Yosefpour, Z. SajadiSeresht, A. Investigating the Role of Education in Reducing Students' Ethical Abnormalities in Different Educational Periods. Second National Conference on Sustainable Development in Educational Sciences and Psychology, Social and Cultural Studies. (In Persian), 2015.
17- Smetana JG. Talking the Talk and Walking the Walk: Conversational Pathways to Moral Development. Hum. Dev. 2016; 58(4-5): 301-307.

18- Tabatabaee, A., Hasani, P., Mortazavi, H., \& Tabatabaeichehr, M. Strategies to enhance rigor in qualitative research. Journal of North Khorasan University of Medical Sciences, 2013; 5(3), 663-670. (In Persian).

19- Ludwig, J. A., QUARTET, L., Reynolds, J. F., \& Reynolds, J. F. Statistical ecology: a primer in methods and computing (Vol. 1). John Wiley \& Sons.1988.

20- Hooman, H. Practical Guide to Qualitative Research. Samt Publications, Tehran. Humanities Research and Development Center, 2005. (In Persian).

21- Aultman JM. A description of inter-professional ethics education in a United States college of pharmacy. Pharm. Educ. 2018; 18-25.

22- Imanipour M. Ethical principles in education. IJHE, 2012; 5(6): 28-41. (In Persian).

23- Janbozorgy M, Noury N \&Agah M. The Training of Ethics, social behavior and legality to children's. Fifth Edition, Tehran, Arjmand Publications, 2014. (In Persian).

24- KhosrowpanahA. The relationship between religion and ethics from the perspective of Master Mesbah, $\mathrm{Q}$ J.KetabehNaghd. 2015; 30: 22-40. (In Persian). 